\title{
Nontraumatic Epidermoid Inclusion Cyst of Vulva in a Young Unmarried Female: A Rare Entity
}

\author{
${ }^{1}$ Anu Nagpal, ${ }^{2}$ Praveen Mohan, ${ }^{3}$ Tejinder Kaur
}

\begin{abstract}
Epidermoid inclusion cysts are the most common types of simple dermal epithelial benign lesions, presenting as wellencapsulated subepidermal mobile nodules. They arise on hair-bearing areas but vulva is a rare site. We here report clinical and ultrasonography (USG) findings of a big epidermal nontraumatic inclusion epidermoid cyst at the vulva which was excised and histopathological examination confirmed diagnosis of epidermoid inclusion cyst without any dysplasia.
\end{abstract}

Keywords: Epidermoid inclusion cyst, Vulva, Nontraumatic.

How to cite this article: Nagpal A, Mohan P, Kaur T. Nontraumatic Epidermoid Inclusion Cyst of Vulva in a Young Unmarried Female: A Rare Entity. J South Asian Feder Obst Gynae 2014;6(3):173-175.

\section{Source of support: Nil \\ Conflict of interest: None}

\section{INTRODUCTION}

Epidermoid inclusion cysts are the most common types of simple epithelial lesions, a result of the implantation of epidermal elements in the dermis showing wellencapsulated subepidermal mobile nodules. ${ }^{1}$ These are probably caused due to traumatic implantation of the epidermis into the dermis or subcutis, during genital mutilations, such as circumcisions widely prevalent in African countries. They arise in hair-bearing areas of the body, including the scalp, face, neck, trunk and back. ${ }^{1-3}$ Less than $10 \%$ of epidermal inclusion cysts occur on the extremities, and even fewer occur on the palms, soles of the feet, and breast. ${ }^{1,3-5}$ The vulva is a rare site. ${ }^{6}$ Epidermoid cysts are filled with keratin debris and are bounded by a wall of stratified squamous epithelium. ${ }^{7}$ Most of the cysts remain asymptomatic except for

\footnotetext{
${ }^{1}$ Junior Resident, ${ }^{2}$ Professor and Head, ${ }^{3}$ Associate Professor

${ }^{1-3}$ Department of Gynecology and Obstetrics, MM Institute of Medical Sciences and Research, Mullana, Ambala, Haryana India
}

Corresponding Author: Anu Nagpal, Department of Gynecology and Obstetrics, MM Institute of Medical Sciences and Research, Mullana, Ambala, Haryana-133203, India Phone: 8059931985, Fax: 01731304550, e-mail: free2sizzle@ rediffmail.com presentation with a palpable superficial nodule. However, if these lesions grow large enough to disturb the normal function of the surrounding structures, become infected, or rupture into the adjacent soft tissue, they may become symptomatic. Epidermoid cysts are benign lesions; however, very rare cases of various associated malignancies have been reported. ${ }^{8}$ We are presenting this case because vulva is a rare site, for nontraumatic epidermoid inclusion cyst.

\section{CASE REPORT}

A 23 years old unmarried nulligravid girl presented with a complaint of swelling in the vulval region since 7 to 8 years. The swelling was initially very small in size but had gradually increased in size over the past 6 months to a size of $8 \times 5 \mathrm{~cm}$. The patient then started feeling discomfort and pain during walking. She had no complaint of pain at rest or discharge from the site of the swelling. There were no bladder and bowel complaints. There was no history of any trauma or circumcision. Her menstrual cycles were unremarkable.

On physical examination the patient had stable vitals. The remarkable findings were on genital examination which showed a soft, cystic swelling on left labia majora of size approximately $8 \times 5 \mathrm{~cm}$ (Fig. 1). There was no local rise of temperature and overlying skin was normal. The swelling was freely mobile, fluctuant and transillumination test was negative. There was no pigmentation or any discharge from the swelling.

Routine blood and urine investigations were within normal limits. Ultrasonography revealed mass which was nonseptate, echo-rich cystic mass, measuring about $10 \times 7 \mathrm{~cm}$ in size (Fig. 2). Keeping in mind the differential diagnosis, the patient was taken up for cyst excision in the operation theater. Under spinal anesthesia (saddle block) an elliptical incision was given over the swelling. The swelling was dissected right above its top by cautery. The swelling was removed en masse and sent for histological examination (Fig. 3). The dead space was obliterated by interrupted sutures. The skin was approximated. The patient was followed up in the gynecology OPD on the 7th postoperative day when the wound was healed. The histopathology examination revealed an epidermoid inclusion cyst of the vulva with 


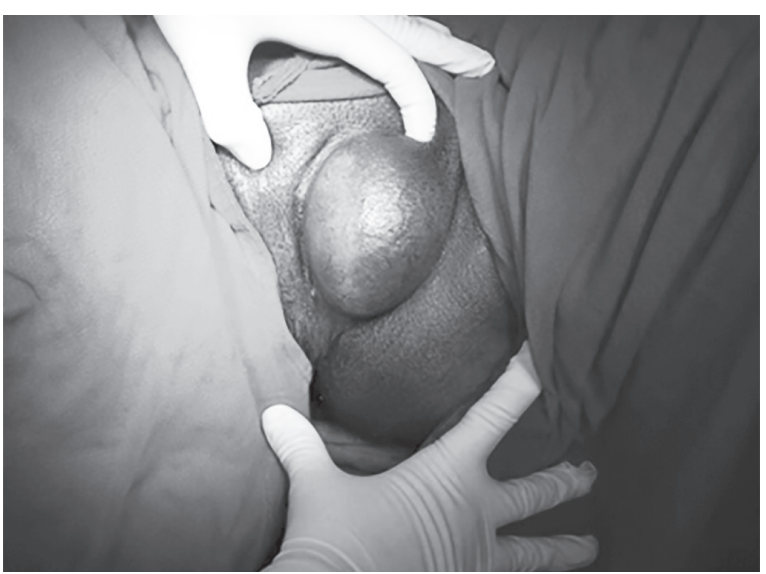

Fig. 1: Clinical picture showing swelling in vulva

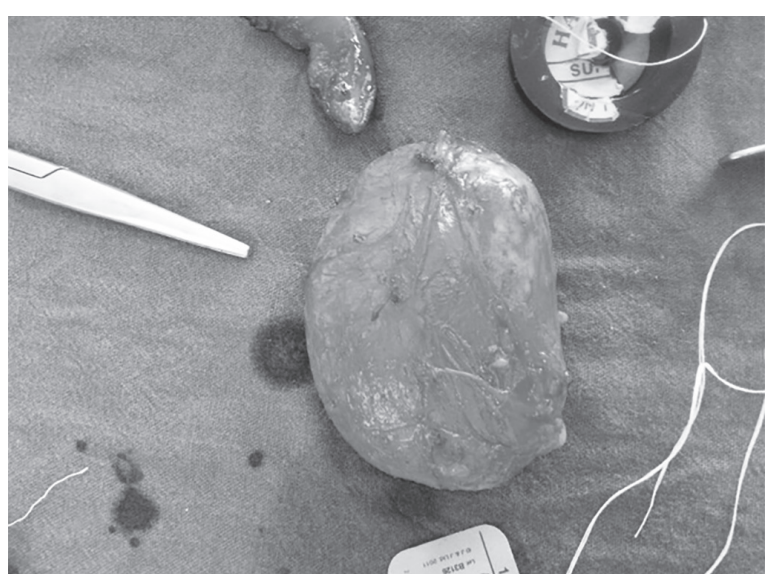

Fig. 3: Extracted cyst

no dysplasia. Patient is under regular follow-up for last 6 months with no further complaints.

\section{DISCUSSION}

Epidermoid cysts are slow growing intradermal keratinizing cysts lined by squamous epithelium. The cysts result from ingrowth or implantation of epidermal tissue underneath other tissues. Analysis of their lipid pattern demonstrates similarities to the epidermis. In addition, epidermoid cysts express cytokeratins 1 and 10, which are constituents of the suprabasilar layers of the epidermis. The source of this epidermis is nearly always the infundibulum of the hair follicle, as evidenced by the observation that the lining of the two structures is identical. ${ }^{9}$

The accumulation of epidermal desquamations, secretions and other debris in a closed space leads to the formation of a cystic and often painless swelling that gradually increases in size over time. ${ }^{6}$ The common sites of involvement are face, trunk, neck, extremities and scalp. The vulva is a rare site. Several mechanisms of epidermal inclusion cyst formation have been suggested, such as misplacement of remnant ectodermal tissues

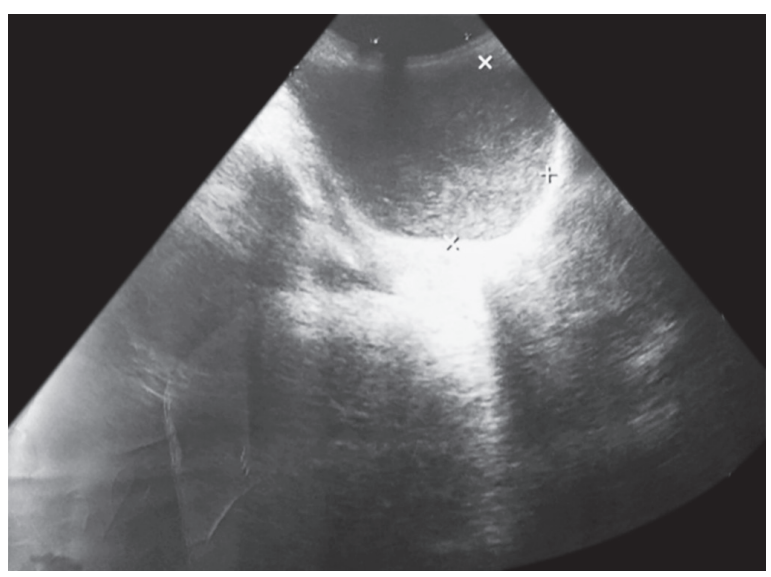

Fig. 2: Picture depicting ultrasonographic findings

during embryogenesis, ${ }_{10}^{10}$ occlusion of the pilosebaceous unit, and traumatic or surgical implantation of epithelial elements. ${ }^{11,12}$ Additionally, in the development of palmoplantar epidermal inclusion cysts, human papillomavirus type 57 or 60 infections may be additional factors. ${ }^{13,14}$

Though histopathologically similar, the pathogenesis of epidermoid cysts of the vulva differ from that of cysts arising from hairy (acne prone) areas, such as the face, neck which arise from the damage to the pilosebaceous unit. ${ }^{15}$ But on the vulva, these cysts result from the burial of fragments of the skin following female genital cutting, vulval trauma, perineal tears and episiotomy. ${ }^{16}$ The cysts are usually asymptomatic unless they become large enough to interfere with function, become infected, or rupture causing inflammation of adjacent structures. ${ }^{17}$ Usually, these masses are midline and most reports place them along the median raphe. In our patient, the mass presented as a palpable soft cystic swelling on left labia majora. Our patient denied any history of trauma to explain the aberrant location and probable mechanism in our case could have been misplacement of remnant ectodermal tissues during embryogenesis. In traumatic cases, the frequency and delay from circumcision to development of inclusion cyst are extremely variable. The delayed development of inclusion cysts after circumcision is postulated to be secondary to unopposed estrogenic stimulation of the embedded epidermal tissue and sebaceous glands during anovulatory menstrual cycles of adolescence. ${ }^{15}$ Probably, same is the reason for gradual increase of size over a long duration in nontraumatic cysts also.

The clinical presentation of patients is variable. Most epidermoid cysts are often asymptomatic. Pain, discomfort, or rupture of cysts during sexual intercourse or vaginal delivery may force patients to seek medical care early. Though our patient had mild pain and discomfort, she did not seek the medical care till she was about to get married. 
Complication of epidermoid inclusion cysts includes rupture and release of keratin leading to intense inflammatory reaction, infection, hematoma and rarely carcinomas.

The differential diagnosis of epidermal inclusion cysts in the superficial soft tissue layer includes other cystic lesions, solid masses and vascular lesions. Especially for cases of ruptured epidermal inclusion cysts, inflammatory changes, such as abscesses, complicated ganglion cysts, complicated bursitis, and neoplastic solid masses should be included in the differential diagnosis. ${ }^{18}$

On ultrasound, epidermoid inclusion cysts appear as well-circumscribed round or oval hypoechoic lesions with scattered echogenic reflectors and no evidence of internal blood flow on Doppler and it helps in differential diagnosis. But, diagnosis of epidermoid inclusion cysts is confirmed by histologic examination which was done in our case also and revealed the typical finding of cyst lined by keratinized stratified squamous epithelium. ${ }^{6}$

The management of inclusion cysts is surgical excision which was done in our patient, which resulted in satisfactory clinical and cosmetic outcomes.

\section{REFERENCES}

1. Greer KE. Epidermal inclusion cyst of the sole. Arch Dermatol 1974;109(2):251-252.

2. Vincent LM, Parker LA, Mittelstaedt CA. Sonographic appearance of an epidermal inclusion cyst. J Ultrasound Med 1985;4(11):609-611.

3. Misner SC, Mariash SA, Alvarez G. Ruptured plantar epidermal inclusion cyst with foreign body giant cell reaction. J Foot Surg 1991;30(1):38-42.

4. Cooper RA, Ramamurthy L. Epidermal inclusion cysts in the male breast. Can Assoc Radiol J 1996;47(2):92-93.
5. Denison CM, Ward VL, Lester SC, et al. Epidermal inclusion cysts of the breast: three lesions with calcifications. Radiology 1997;204(2):493-496.

6. Kroll GL, Miller L. Vulvar epithelial inclusion cyst as a late complication of childhood female traditional genital surgery. Am J Obstet Gynecol 2000;183(2):509-510.

7. Bullough PG. Benign non-matrix-producing bone tumors. In: Bullough PG, editors. Orthopaedic Pathology. 3rd ed. New York, NY: CV Mosby Co; 1997. p. 397-432.

8. Aloi F, Tomasini C, Pippione M. Mycosis fungoides and eruptive epidermoid cysts: a unique response of follicular and eccrine structures. Dermatology 1993;187(4):273-277.

9. Swygert KE, Parrish CA, Cashman RE, Lin R, Cockerell CJ. Melanoma in situ involving an epidermal inclusion (infundibular) cyst. Am J Dermatopathol 2007 Dec;29(6):564-565.

10. McLendon RE. Epidermoid and dermoid tumors. In: Wilkins RH, Rengachary SS, editors. Neurosurgery. 2nd ed. New York, NY: Mc Graw-Hill; 1996. p. 959-963.

11. Fisher AR, Mason PH, Wagenhals KS. Ruptured plantar epidermal inclusion cyst. Am J Roentgenol 1998;171(6):1709-1710.

12. Ward WA, Labosky DA. Ruptured epidermal inclusion cyst of the palm presenting as color-button abscess. J Hand Surg Am 1985;10(6 pt 1):899-901.

13. Kashima M, Takahama, Baba T, et al. Detection of human papillomavirus type 57 in the tissue of a plantar epidermoid cyst. Dermatology 2003;207(2):185-187.

14. Lee S, Lee W, Chung S, et al. Detection of human papillomavirus 60 in epidermal cysts of non-palmoplantar location. Am J Dermatopathol 2003;25(3):243-247.

15. Rizk DE. A large clitoral epidermoid inclusion cyst first presenting in adulthood following childhood circumcision. J Obstet Gynaecol 2007;14:445-448.

16. Somesh G, Sanjeev G, Vijay Kumar J, Bhushan K. A 'stone' in the vulva. Sex Transm Inf 2000;14:319.

17. Shah KH, Maxted WC, Chun B. Epidermoid cysts of the testis: a report of three cases and an analysis of 141 cases from the world literature. Cancer 1981;47(3):577-582.

18. Hong SH, Chung HW, Choi JY, Koh YH, Choi JA, Kang HS. MRI findings of subcutaneous epidermal cysts: emphasis on the presence of rupture. AJR Am J Roentgenol 2006;186:961-966. 